\title{
COUNTING SETS WITH EXCEPTIONS
}

\section{G. MOLTENI}

Abstract. Let $S \subseteq \mathbb{N}$ be a set of integers, $S_{x} \stackrel{\text { def }}{=} \cap[0, x], X \stackrel{\text { def }}{=} \sharp S_{x}$ and let $\tilde{S} \subseteq S$ be the "expectional" set, $\tilde{S}_{x} \stackrel{\text { def }}{=} \tilde{S} \cap[0, x], E \stackrel{\text { def }}{=} \sharp \tilde{S}_{x}$. An upper bound for the fraction of subsets of $S_{x}$ having $N$ elements and intersecting $K$ times at least the set $\tilde{S}$ is proved when $N, E, X \rightarrow \infty$.

Mathematics subject classification (2000): 05A20.

Key words and phrases: exceptional set.

\section{REFERENCES}

[1] G. E. AndREws, R. ASKEY, R. RoY, Special Functions, Encyclopedia of Mathematics and its Applications, Vol. 71, Cambridge University Press, 1999.

[2] J. BRÜDERN, A. PERELLI, A note on the distribution of sumsets, to appear. 